\title{
Palladium-Based Supramolecularly Regulated Catalysts for Asymmetric Allylic Substitutions
}

\author{
Laura Rovira, ${ }^{\dagger, \&}$ Héctor Fernández-Pérez ${ }^{\dagger, \&}$ and Anton Vidal-Ferran ${ }^{*}, \dagger, \&, \ddagger$ \\ ${ }^{\dagger}$ Institute of Chemical Research of Catalonia (ICIQ), Avgda. Països Catalans 16, 43007 Tarragona, Spain \\ \& The Barcelona Institute of Science and Technology, Avgda. Països Catalans 16, 43007 Tarragona, Spain \\ * Catalan Institution for Research and Advanced Studies (ICREA), Passeig Lluís Companys 23, 08010 Barcelona \\ Supporting Information
}

\begin{abstract}
Herein is reported the effect of different polyether binders (alkali metal, alkaline earth metal and lanthanide salts) as regulation agents to enhance the catalytic properties of palladium complexes derived from enantiopure bisphosphite ligands in allylic substitutions. The addition of RbOAc or $\mathrm{M}(\mathrm{OTf})_{\mathrm{x}}\left(\mathrm{M}=\mathrm{Mg}^{2+}, \mathrm{La}^{3+}\right.$ or $\left.\mathrm{Ho}^{3+}\right)$ led to positive effects in enantioselectivity (by up to $16 \%$ ee) for the allylic substitution reactions. These ligands coordinated in the usual cis-fashion or in an unprecedented transfashion to the palladium center, depending on the phosphite group, and presented different reactivity in the allylic substitutions.
\end{abstract}

\section{INTRODUCTION}

The search for efficient chiral catalysts for the broadest possible substrate scope in a given transformation is still a cuttingedge research goal, as structural changes to the substrate(s) and or reagent(s) often translate into a loss of enantioselectivity. Within the supramolecular enantioselective catalysis arena, ${ }^{1}$ progress has been made in regulating the size and shape of the chiral catalyst, ${ }^{2}$ or in modifying the first-sphere coordination geometry of the active metal. ${ }^{3}$ However, there are few examples of fine-modification of the geometry of the activesite that do not imply major alteration of the principal structural features of the enantioselective catalyst. ${ }^{4,5}$

Fan et al. pioneered the use of supramolecularly regulated polyether-based ligands for rhodium-mediated hydrogenations. ${ }^{5 b}$ These authors reported the first example on the use of rhodium complexes derived from bisphosphite-polyether ligands in asymmetric hydrogenation, whose catalytic performance in terms of enantioselectivity was enhanced by the addition of a regulation agent (RA, Figure 1) ${ }^{5 b}$ Later, we also demonstrated that conformationally transformable bisphosphite ligands $s^{4 a-c}$ incorporating polyether groups behaved as supramolecularly regulated ligands in asymmetric hydroformylations $^{4 a-c}$ and hydrogenations ${ }^{4 \mathrm{~b}}$ (Figure 1). We showed that enantioselectivities in the transformation of interest can be maximized by the choice of whether or not to use an RA (and if so, which one) ${ }^{4 a-c}$ Computational studies revealed that the significant increase in enantiomeric excess provided by the RAs in hydroformylation reactions resulted from adaptation of the P-Rh-P bond angle $(\beta){ }^{4 b}$

Pd-mediated allylic substitutions represent an efficient transformation to stereoselectively form $\mathrm{C}-\mathrm{C}$ and $\mathrm{C}-\mathrm{X}$ bonds. ${ }^{6}$
Palladium complexes derived from $P$ ligands are efficient catalysts for the reaction between allylic alcohol derivatives and nucleophiles, ${ }^{7}$ which have often been generated in situ from the protonated nucleophile (i.e. a malonic ester) in the presence of $\mathrm{N}, \mathrm{O}$-bis(trimethylsilyl)-acetamide (BSA) and catalytic amounts of an alkali metal salt. ${ }^{8}$

Herein we report our efforts in expanding our supramolecular regulation strategy to allylic substitutions. We envisaged that the combination of ligands $1 \mathbf{a}-\mathbf{c}$ with $\mathrm{Pd}$ (II) precursors suitable for this chemistry and an array of metal salts (for both generating the required nucleophile and triggering the regulation mechanism in our ligands) could function as supramolecularly regulated catalysts in allylic substitutions.

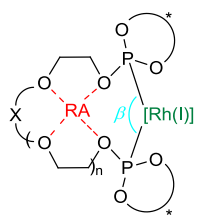

Fan et al.: $.^{[5 b]} \quad \mathrm{X}=-\left(\mathrm{CH}_{2}\right)_{2}-; \mathrm{n}=0$ and $3-5 ; \mathrm{O}-\mathrm{O}=\mathrm{BINOL}$ $\mathrm{RA}=$ alkali metal $\mathrm{BArF}$ salts as RAs for Rh-mediated hydrogenations

Vidal-Ferran $\quad X=O, B I P O L$ and $B I N O L ; n=2,5$ and 7 et al: $:^{[4 a-c]} \quad \mathrm{O}-\mathrm{O}=\mathrm{BIPOL}, \mathrm{BINOL}$ and substituted BINOLs $\mathrm{RA}=$ alkali metal or ammonium BArF salts as RAs for Rh-mediated hydroformylations and hydrogenations

Previous work

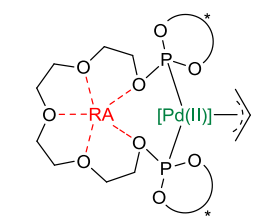

$\mathrm{RA}=$ metal salt as base and regulation agent for $\mathrm{Pd}$-mediated allylic substitutions

This work
Figure 1. Supramolecularly regulated bisphosphite ligands in enantioselective catalysis (BIPOL $=[1,1$ '-biphenyl $]-2,2$ '-diol, $\mathrm{BINOL}=\left[1,1^{\prime}\right.$-binaphthalene $]-2,2^{\prime}$-diol $)$. 


\section{RESULTS AND DISCUSSION}

Ligand Synthesis. We initially designed ligands $\mathbf{1 a}-\mathbf{c}$ by combining the linker group that showed the highest regulation ability in our hydroformylation studies ${ }^{4 \mathrm{~b}}$ (see blue fragment in Figure 2) and an array of stereogenic phosphite groups (see green fragment in Figure 2). Bisphosphites $\mathbf{1 a}$ and $\mathbf{1 b}$ had already been described ${ }^{9,4 b, c}$ and compound 1c was prepared in an analogous manner to $\mathbf{1 a}$ and $\mathbf{1 b}$ : reaction of tetraethylene glycol with two equivalents of the corresponding chlorophosphite in the presence of a base $\left(\mathrm{NEt}_{3}\right)$.

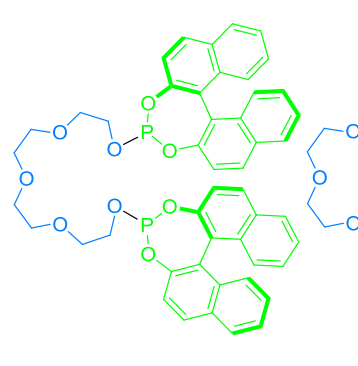

1a

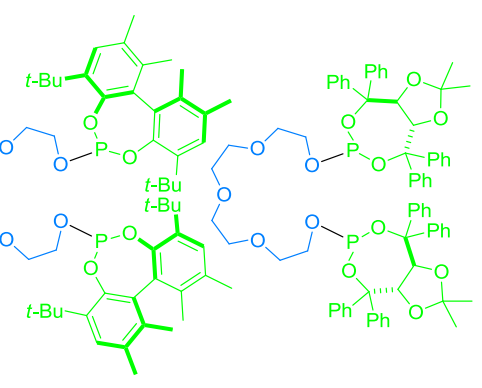

1b

$1 c$
Figure 2. Set of supramolecular bisphosphite ligands 1a-c.

Table 1. Pd-mediated Asymmetric Allylic Alkylation of 2 with Ligands 1a-c and Different Regulation Agents (RAs) ${ }^{a}$

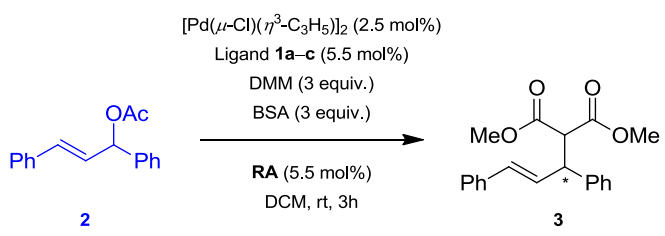

\begin{tabular}{ccccc}
\hline entry & ligand & RA & $\begin{array}{c}\text { conv. } \\
(\%)^{b}\end{array}$ & $\begin{array}{c}\text { ee 3 }(\%, \\
\text { config. }^{c}\end{array}$ \\
\hline 1 & 1a & & $>99$ & $44(R)$ \\
2 & 1a & LiOAc & $>99$ & $21(R)$ \\
3 & 1a & CsOAc & $>99$ & $54(R)$ \\
4 & 1b & & $>99$ & $20(R)$ \\
5 & 1b & LiOAc & $>99$ & $26(R)$ \\
6 & 1b & CsOAc & $>99$ & $26(R)$ \\
$7^{d}$ & 1c & & 60 & $43(S)$ \\
8 & 1c & LiOAc & $>99$ & $24(S)$ \\
$9^{d}$ & 1c & CsOAc & 90 & $39(S)$
\end{tabular}

${ }^{a}$ Reaction conditions are indicated in the above scheme unless otherwise stated. ${ }^{b}$ Determined by ${ }^{1} \mathrm{H}$ NMR spectroscopy. ${ }^{c}$ Determined by HPLC on chiral stationary phases. ${ }^{d}$ Reaction performed at $\mathrm{rt}$ for $24 \mathrm{~h}$.

Pd-mediated Asymmetric Allylic Substitutions. With ligands $\mathbf{1 a}-\mathbf{c}$ in hand, we then assessed their catalytic activity in combination with an array of RAs in allylic substitutions. Initially, we chose 1,3-diphenylallyl acetate $\mathbf{2}$ as the substrate and dimethyl malonate (DMM) as the nucleophile. The precatalysts were generated in situ from $\left[\mathrm{Pd}(\mu-\mathrm{Cl})\left(\eta^{3}-\right.\right.$ $\left.\left.\mathrm{C}_{3} \mathrm{H}_{5}\right)\right]_{2}$, the ligands $\mathbf{1 a}-\mathbf{c}$ and the RA. The reactions were conducted in dichloromethane $\left(\mathrm{CH}_{2} \mathrm{Cl}_{2}\right)$ as we considered that this solvent would provide a compromise between the solubility of the RA and its binding strength with the polyether fragment. ${ }^{4 \mathrm{~b}, 10}$ As illustrated in Table 1 , the palladium complexes derived from bisphosphites $\mathbf{1 a}-\mathbf{c}$ provided active catalysts displaying full conversion in almost all cases (see Table 1). Selectivity in the absence of regulation agents was moderate and highly dependent on the nature of the phosphite fragment.

The palladium complex of ligand 1a incorporating an $\left(S_{\mathrm{a}}\right)$ BINOL-derived phosphite fragment provided the best enantioselectivity (up to $44 \%$ ee, entry 1 in Table 1 ). A similar ee was observed for ligand 1c, although reactivity was lower (see entry 7 in Table 1). Finally, the sterically more demanding phosphite groups in ligand $\mathbf{1 b}$ led to a decrease in ee (see entry 4 in Table 1). As our regulation design allows new catalytic systems to be generated by employing a set of RAs, subsequent attempts to improve enantioselectivity following this strategy (addition of LiOAc or CsOAc) resulted in some cases in higher ee's for ligands $\mathbf{1 a}$ and $\mathbf{1 b}$ (increase of up to $10 \%$ ee, compare entry 1 with 3 in Table 1 ).

We then studied the influence of the Pd precursor on the outcome of the allylic substitutions by incorporating $\left[\mathrm{PdCl}_{2}(\mathrm{cod})\right]$ to our studies (Table 2). Interestingly, $\left[\mathrm{PdCl}_{2}(\mathrm{cod})\right]$ performed better than $\left[\mathrm{Pd}(\mu-\mathrm{Cl})\left(\eta^{3}-\mathrm{C}_{3} \mathrm{H}_{5}\right)\right]_{2}$ in terms of enantioselectivity (for instance, compare entries 1-3 in Table 1 with entries 1, 2 and 9 in Table 2). Of all the RA/ligand combinations tested, RbOAc•1a gave the best results: full conversion and $65 \%$ ee (increase of $6 \%$ ee with respect to when no RA was used, compare entry 1 with 6 in Table 2). Higher amounts of RbOAc did not bring any advantage in the result of the reaction and lower temperatures $\left(0{ }^{\circ} \mathrm{C}\right)$ resulted in no conversion (see entries 7 and 8 in Table 2, respectively). Two different potassium

Table 2. Allylic Alkylations of 2 with Bisphosphite Ligand 1a or 1c and Different RAs ${ }^{a}$

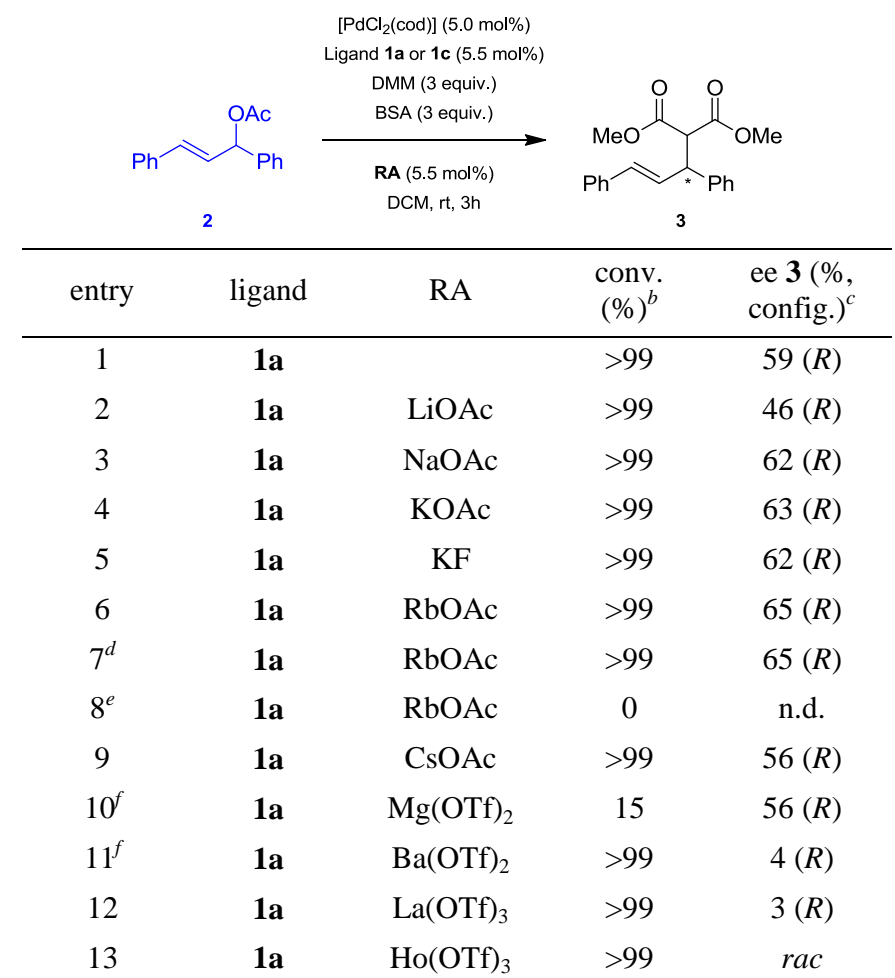




$\begin{array}{lllll}14^{f} & \text { 1c } & & 0 & \text { n.d. } \\ 15^{f} & \text { 1c } & \text { LiOAc } & 0 & \text { n.d. } \\ 16^{f} & \text { 1c } & \text { CsOAc } & 0 & \text { n.d. }\end{array}$

${ }^{a}$ See footnotes a in Table $1 .{ }^{b}$ See footnotes b in Table $1 .{ }^{c}$ See footnotes $\mathrm{c}$ in Table $1 .{ }^{d} 1.7$ equiv of RA relative to Pd precursor was used. ${ }^{e}$ Reaction performed at $0{ }^{\circ} \mathrm{C}$ for $24 \mathrm{~h} .{ }^{f}$ Reaction performed at $\mathrm{rt}$ for $24 \mathrm{~h}$.

salts with different counterions (i.e. KOAc and KF) were used as RAs, and no differences in reactivity were observed (compare entry 4 with 5 in Table 2). It should be noted that the use of alkaline earth metal or lanthanide triflates as RAs led to detrimental effects for both reactivity and selectivity (see entries 10-13 in Table 2). The palladium complex derived from bisphosphite 1c led to inactive catalysts in this chemistry since no reactivity for the allylic alkylation of $\mathbf{2}$ was observed even in the presence of different RAs (see entries 14-16 in Table 2).

We then assessed the supramolecularly regulated catalysts derived from the lead bisphosphite 1a in allylic substitutions using benzylamine (BZA) as a nitrogen nucleophile. Standard screening conditions were used and the results of this study are shown in Table 3. Complexes derived from 1a performed as efficient catalysts in the allylic amination of $\mathbf{2}$ in terms of conversion (see Table 3). When no RAs were used, a low ee was achieved (30\% ee, see entry 1 in Table 3$)$. Interestingly, and in sharp contrast with the results using a $C$-nucleophile, an improvement in ee was obtained by using group II or lanthanides triflates as RAs (increase of up to $16 \%$ ee with $\mathrm{Mg}(\mathrm{OTf})_{2}, \mathrm{La}(\mathrm{OTf})_{3}$ or $\mathrm{Ho}(\mathrm{OTf})_{3}$; see entries 4,7 , and 8 in Table 3) and $\left[\mathrm{Pd}(\mu-\mathrm{Cl})\left(\eta^{3}-\mathrm{C}_{3} \mathrm{H}_{5}\right)\right]_{2}$ as palladium precursor (compare entry 4 with 5 in Table 3 ).

Table 3. Allylic Amination of 2 with Bisphosphite Ligand $1 \mathrm{a}$ and Different RAs ${ }^{a}$

\begin{tabular}{|c|c|c|c|c|c|}
\hline & $\stackrel{\mathrm{O}}{\mathrm{Ac}}_{\mathrm{Ph}}^{\mathrm{Ac}}$ & $\begin{array}{r}{[\mathrm{Pd]}(5.0} \\
\text { Ligand } 1 \mathbf{a} \\
\text { BZA }(3 \\
\text { BSA }(3\end{array}$ & $\begin{array}{l}\text { lol\%) } \\
5 \text { mol\%) } \\
\text { uiv.) } \\
\text { uiv.) }\end{array}$ & $\mathrm{HN}$ & \\
\hline entry & ligand, $\mathrm{Pd}-1$ & ecursor & RA & $\begin{array}{c}\text { conv. } \\
(\%)^{b}\end{array}$ & $\begin{array}{l}\text { ee } 4(\%, \\
\text { config. })^{c}\end{array}$ \\
\hline 1 & 1a, $[\operatorname{Pd}(\mu-\mathrm{Cl})$ & $\left.\left.{ }^{3}-\mathrm{C}_{3} \mathrm{H}_{5}\right)\right]_{2}$ & & $>99$ & $30(S)$ \\
\hline $2^{d}$ & 1a, $[\operatorname{Pd}(\mu-\mathrm{Cl})$ & $\left.\left.{ }^{3}-\mathrm{C}_{3} \mathrm{H}_{5}\right)\right]_{2}$ & $\mathrm{LiOAc}$ & $>99$ & $33(S)$ \\
\hline 3 & 1a, $[\operatorname{Pd}(\mu-\mathrm{Cl})$ & $\left.\left.{ }^{3}-\mathrm{C}_{3} \mathrm{H}_{5}\right)\right]_{2}$ & $\mathrm{CsOAc}$ & 0 & n.d. \\
\hline 4 & 1a, $[\mathrm{Pd}(\mu-\mathrm{Cl})$ & $\left.\left.{ }^{3}-\mathrm{C}_{3} \mathrm{H}_{5}\right)\right]_{2}$ & $\operatorname{Mg}(\mathrm{OTf})_{2}$ & $>99$ & $46(S)$ \\
\hline 5 & 1a, $[\mathrm{PdCl}$ & $(\operatorname{cod})]$ & $\operatorname{Mg}(\mathrm{OTf})_{2}$ & 35 & $29(S)$ \\
\hline 6 & 1a, $[\mathrm{Pd}(\mu-\mathrm{Cl})$ & $\left.\left.1^{3}-\mathrm{C}_{3} \mathrm{H}_{5}\right)\right]_{2}$ & $\mathrm{Ba}(\mathrm{OTf})_{2}$ & $>99$ & $45(S)$ \\
\hline 7 & 1a, $[\operatorname{Pd}(\mu-\mathrm{Cl})$ & $\left.\left.\eta^{3}-\mathrm{C}_{3} \mathrm{H}_{5}\right)\right]_{2}$ & $\mathrm{La}(\mathrm{OTf})_{3}$ & $>99$ & $46(S)$ \\
\hline 8 & 1a, $[\operatorname{Pd}(\mu-\mathrm{Cl})$ & $\left.\left.-\mathrm{C}_{3} \mathrm{H}_{5}\right)\right]_{2}$ & $\mathrm{Ho}(\mathrm{OTf})_{3}$ & $>99$ & $46(S)$ \\
\hline
\end{tabular}

Finally, we tested our set of supramolecular bisphosphite ligands in the Pd-mediated allylic substitution of cinnamyl acetate $\mathbf{5}$ using DMM as nucleophile under standard screening conditions (Table 4). In general terms, palladium complexes derived from bisphosphites $\mathbf{1}$ were efficient catalysts in the alkylation of substrate $\mathbf{5}$ in terms of conversion (see Table 4). As expected for palladium-based catalysts, ${ }^{7 \mathrm{~d}, \mathrm{e}}$ and in the absence of regulation agents, either low branched-to-linear ratios (b/l ratio, see entries 1 and 4 in Table 4 ) or exclusively the linear product 7 (see entries 5 and 12 in Table 4) were achieved depending on both the bisphosphite and the palladium precursor (see results for ligand $\mathbf{1 b}$, compare entry 4 with 5 in Table 4). In terms of enantioselectivity, a respectable value of $60 \%$ ee at a b/l ratio of $12 / 88$ was achieved by using the palladium complex derived from $\mathbf{1 b}$ and $\left[\mathrm{Pd}(\mu-\mathrm{Cl})\left(\eta^{3}-\right.\right.$ $\left.\left.\mathrm{C}_{3} \mathrm{H}_{5}\right)\right]_{2}$ (see entry 4 in Table 4 ). Interestingly, the use of Li$\mathrm{OAc}$ or CsOAc as RAs led to an increase in the regioselectivity of the reaction for the palladium complex derived of $\mathbf{1 a}(\mathrm{b} / \mathrm{l}$ ratio up to 17/83; entries 2 and 3 in Table 4). ${ }^{7}$ Unfortunately, the enantioselectivity could not be further improved for those catalytic systems leading to the highest ratio of branched product.

Table 4. Allylic Alkylation of 5 with Bisphosphite Ligands 1a-c and Different RAs ${ }^{a}$

\begin{tabular}{|c|c|c|c|c|c|}
\hline 5 & $\begin{array}{r}{[\mathrm{Pd}(\mu-\mathrm{Cl})} \\
\text { Ligan }\end{array}$ & $\begin{array}{l}\left.\left.\mathrm{C}_{3} \mathrm{H}_{5}\right)\right]_{2}(2.5 \mathrm{~mol} \%) \\
\text { a-c }(5.5 \mathrm{~mol} \%) \\
1(3 \text { equiv. }) \\
\text { (3 equiv.) } \\
\underset{5.5 \mathrm{~mol} \%)}{\mathrm{M}, \mathrm{rt}, 2 \mathrm{~h}}\end{array}$ & 策 & \multicolumn{2}{|r|}{7} \\
\hline entry & ligand & RA & $\begin{array}{l}\text { conv. } \\
(\%)^{b}\end{array}$ & $\begin{array}{c}\mathbf{6} / 7 \\
\text { ratio }^{b}\end{array}$ & $\begin{array}{l}\text { ee } \mathbf{6}(\%, \\
\text { config. })^{c}\end{array}$ \\
\hline 1 & $1 \mathbf{a}$ & & $>99$ & $14 / 86$ & $28(R)$ \\
\hline 2 & $1 \mathrm{a}$ & $\mathrm{LiOAc}$ & $>99$ & $17 / 83$ & $19(R)$ \\
\hline 3 & $1 \mathbf{a}$ & $\mathrm{CsOAc}$ & $>99$ & $17 / 83$ & $32(R)$ \\
\hline 4 & $1 b$ & & $>99$ & $12 / 88$ & $60(R)$ \\
\hline $5^{d}$ & $1 b$ & & 75 & $>1 / 99$ & n.d. \\
\hline 6 & $1 b$ & LiOAc & $>99$ & $14 / 86$ & $57(R)$ \\
\hline 7 & $1 b$ & $\mathrm{CsOAc}$ & $>99$ & $11 / 89$ & $55(R)$ \\
\hline 8 & $1 b$ & $\operatorname{Mg}(\mathrm{OTf})_{2}$ & $>99$ & $15 / 85$ & $50(R)$ \\
\hline 9 & $1 b$ & $\mathrm{Ba}(\mathrm{OTf})_{2}$ & 0 & n.d. & n.d. \\
\hline 10 & $1 b$ & $\mathrm{La}(\mathrm{OTf})_{3}$ & $>99$ & $12 / 88$ & $42(R)$ \\
\hline 11 & $1 b$ & $\mathrm{Ho}(\mathrm{OTf})_{3}$ & 0 & n.d. & n.d. \\
\hline 12 & $1 c$ & & $>99$ & $>1 / 99$ & n.d. \\
\hline 13 & $1 c$ & LiOAc & $>99$ & $>1 / 99$ & n.d. \\
\hline 14 & 1c & $\mathrm{CsOAc}$ & $>99$ & $>1 / 99$ & n.d. \\
\hline
\end{tabular}

${ }^{a}$ See footnotes a in Table $1 .{ }^{b}$ See footnotes b in Table $1 .{ }^{c}$ See footnotes c in Table $1 . .{ }^{d}\left[\mathrm{PdCl}_{2}(\mathrm{cod})\right](5.0 \mathrm{~mol} \%)$ was used as metal precursor and the reaction was performed at $\mathrm{rt}$ for $6 \mathrm{~h}$.

Coordination studies. After having studied bisphosphite ligands 1a-c in Pd-mediated allylic substitutions, we carried out coordination studies in order to gain insight into the reactivity of the palladium precatalysts derived from 1a and 1c (see Table 2) as well as into the regulation mechanism. The reaction of bisphosphites $\mathbf{1 a}$ and $\mathbf{1 c}$ with $\left[\mathrm{PdCl}_{2}(\mathrm{cod})\right]$ proceeded smoothly to provide the corresponding palladium complexes $\left[\mathrm{PdCl}_{2}(\mathbf{1 a})\right](\mathbf{8 a})$ and $\left[\mathrm{PdCl}_{2}(\mathbf{1 c})\right](\mathbf{8 c})$, which were isolated and characterized. The ${ }^{31} \mathrm{P}\left\{{ }^{1} \mathrm{H}\right\}$ NMR spectra for 
compounds 8a and 8c showed single resonances at 109.8 and 90.2 ppm, respectively. ${ }^{11}$ It is interesting to note that the signal of TADDOL-based bisphosphite $\mathbf{8 c}$ was shielded upfield with respect to the signal of $8 \mathbf{a}(\Delta \delta \approx 20 \mathrm{ppm})$, which might hint at important structural differences between palladium complexes $\mathbf{8 a}$ and $8 \mathbf{c}$. Interestingly, compounds $8 \mathbf{a}$ and $\mathbf{8 c}$ could be crystallized, and X-ray analysis unambiguously established their structures. ${ }^{12}$ For 8a, the palladium center had a distorted square-planar geometry in which the two phosphorus groups of ligand 1a were coordinated in a cis-fashion (see Figure 3 and Table 5). Meanwhile in complex 8c, the palladium center also displayed a square-planar geometry but with the phosphorus groups of ligand 1c occupying trans-binding sites (see Figure 3 and Table 5). To the best of our knowledge, this is the first reported example of a trans-chelating bisphosphite in Pd complexes, which appears to be bound to a lack of reactivity in this chemistry (see entries $14-16$ in Table 2). Finally, to support our hypothesis on the regulation mechanism, we studied the interaction of RbOAc with the regulation site of the highest-performing palladium complex 8a. NMR analysis qualitatively demonstrated the binding of RbOAc within the polyethyleneoxy moieties: the addition of incremental amounts of RbOAc to a solution of 8a (up to 1.7 equiv.) caused significant changes to the chemical shift, multiplicity, and signal width of the polyethyleneoxy fragments. ${ }^{12}$ These results suggest that binding of RbOAc within the polyethyleneoxy moieties is involved in the regulation effects mediated by the RA in the described allylic substitutions.
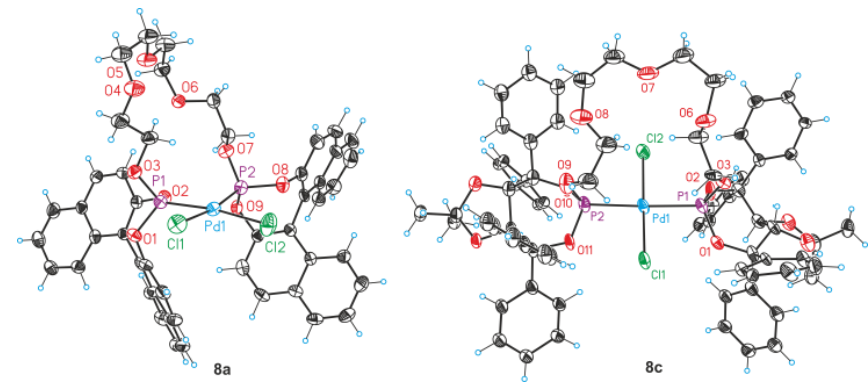

Figure 3. Crystal structures of $\mathbf{8 a}$ and 8c (ORTEP drawings showing in both cases thermal ellipsoids at $30 \%$ probability).

Table 5. Selected Bond Lengths $(\AA)$ and Angles $\left(^{\circ}\right)$ for Palladium Complexes 8a and 8c.

\begin{tabular}{cccc}
\hline \multicolumn{2}{c}{ Compound 8a } & \multicolumn{2}{c}{ Compound 8c } \\
Atoms & $\begin{array}{c}\text { Lengths }(\AA) \\
\text { or Angles }\left({ }^{\circ}\right)\end{array}$ & Atoms & $\begin{array}{c}\text { Lengths }(\AA) \\
\text { or Angles }\left({ }^{\circ}\right)\end{array}$ \\
\hline Pd1-P1 & $2.2141(17)$ & Pd1-P1 & $2.287(2)$ \\
Pd1-P2 & $2.2191(16)$ & Pd1-Cl1 & $2.291(2)$ \\
Pd1-Cl2 & $2.3113(17)$ & Pd1-Cl2 & $2.291(2)$ \\
Pd1-Cl1 & $2.3450(16)$ & Pd1-P2 & $2.301(2)$ \\
P1-Pd1-P2 & $92.45(6)$ & P1-Pd1-Cl1 & $91.30(7)$ \\
P1-Pd1-Cl2 & $172.10(6)$ & P1-Pd1-Cl2 & $88.36(8)$ \\
P2-Pd1-Cl2 & $93.27(6)$ & Cl1-Pd1-Cl2 & $174.58(10)$ \\
P1-Pd1-Cl1 & $83.41(6)$ & P1-Pd1-P2 & $177.39(8)$ \\
P2-Pd1-Cl1 & $171.04(5)$ & Cl1-Pd1-P2 & $91.30(7)$ \\
C12-Pd1-Cl1 & $91.66(6)$ & Cl2-Pd1-P2 & $89.07(8)$
\end{tabular}

\section{CONCLUSIONS}

In summary, we designed and prepared supramolecularly regulated ligands for Pd-mediated asymmetric allylic substitutions. The selectivity (both regio- and stereoselectivity) of the allylic substitutions mediated by bisphosphites $\mathbf{1}$ could be regulated by using several alkali metal, alkaline earth metal or lanthanide salts as regulation agents. Positive increments in the regio- and enantioselectivity were achieved in the allylic substitutions of benchmark substrates using carbon and nitrogen nucleophiles. The distinct reactivity between $\mathbf{8 a}$ and $\mathbf{8 c}$ in allylic substitution reactions may be attributed to the different coordination mode of bisphosphite ligands 1a and 1c with $\left[\mathrm{PdCl}_{2}(\mathrm{cod})\right]$ (in a cis- or trans-fashion, respectively), as demonstrated by $\mathrm{X}$-ray single crystal analysis.

\section{EXPERIMENTAL SECTION}

General considerations. All syntheses were carried out using chemicals as purchased from commercial sources unless otherwise cited. All manipulations and reactions were performed under inert atmosphere. Glassware was dried in vacuo before use with a hot air gun. All solvents were dried and deoxygenated by using a Solvent Purification System (SPS). Silica gel 60 (230-400 mesh) or $\mathrm{C} 18-\mathrm{SiO}_{2}(200-400$ mesh) was used for column chromatography. NMR spectra were recorded in $\mathrm{CDCl}_{3}$ unless otherwise cited. ${ }^{1} \mathrm{H}$ NMR and ${ }^{13} \mathrm{C}$ NMR chemical shifts were quoted in ppm relative to residual solvent peaks, whereas ${ }^{31} \mathrm{P}\left\{{ }^{1} \mathrm{H}\right\}$ NMR chemical shifts were quoted in ppm relative to $85 \%$ phosphoric acid in water. Highresolution mass spectra (HRMS) were recorded by using an electrospray ionization (ESI) method in positive mode or matrix-assisted laser desorption/ionization (MALDI) method, respectively. Melting points were determined in open capillaries and are uncorrected. Enantiomeric excesses were determined by HPLC equipped with a diode array detector using chiral stationary phases.

General synthetic procedure for bisphosphite ligands (1a-c). Under inert atmosphere, the chlorophosphites (1 equiv) were dissolved in anhydrous toluene $(25 \mathrm{~mL}$ per mmol of the chlorophosphites) and $\mathrm{NEt}_{3}$ (3 equiv). A solution of tetraethylene glycol (0.46 equiv., in $50 \mathrm{~mL}$ of toluene per mmol of tetraethylene glycol) was slowly added to the previous solution and allowed to react overnight at $\mathrm{rt}$. The reaction mixture was filtered and the solvent evaporated in уасио. The resulting crude mixtures were purified by column chromatography on $\mathrm{C} 18-\mathrm{SiO}_{2}$ using acetonitrile/ethyl acetate $1: 1$ as elution solvent to provide the expected bisphosphites 1 as white solids.

Compound 1c. Compound 1c was synthesised from TADDOLderived chlorophosphite ${ }^{13}(1.44 \mathrm{~g}, 2.71 \mathrm{mmol})$ and a slow addition of tetraethylene glycol $(243.0 \mathrm{mg}, 1.25 \mathrm{mmol})$ with $\mathrm{NEt}_{3}(0.52 \mathrm{~mL}, 3.75$ mmol) as base. Purification by $\mathrm{C} 18-\mathrm{SiO}_{2}$ column chromatography afforded the expected bisphosphite ligand $1 \mathrm{c}$ as a white solid $(1.05 \mathrm{~g}$, $71 \%$ yield). mp $90.3-95.3{ }^{\circ} \mathrm{C} .[\alpha]_{\mathrm{D}}{ }^{24}+162.4\left(c 0.39\right.$ in $\left.\mathrm{CH}_{2} \mathrm{Cl}_{2}\right) .{ }^{1} \mathrm{H}$ NMR $\left(400 \mathrm{MHz}, \mathrm{CDCl}_{3}\right) \delta 0.57(6 \mathrm{H}, \mathrm{s}), 0.91(6 \mathrm{H}, \mathrm{s}), 3.40-3.48(4 \mathrm{H}$, $\mathrm{m}), 3.53-3.61(8 \mathrm{H}, \mathrm{m}), 3.85-4.02(4 \mathrm{H}, \mathrm{m}), 5.06\left(2 \mathrm{H}, \mathrm{dd},{ }^{3} J_{\mathrm{H}, \mathrm{H}}=8.3\right.$ $\left.\mathrm{Hz},{ }^{4} J_{\mathrm{H}, \mathrm{P}}=1.8 \mathrm{~Hz}\right), 5.19\left(2 \mathrm{H}, \mathrm{d},{ }^{3} J_{\mathrm{H}, \mathrm{H}}=8.3 \mathrm{~Hz}\right), 7.19-7.36(24 \mathrm{H}, \mathrm{m})$, 7.42-7.45 (4H, m), 7.50-7.60 (12H, m). ${ }^{13} \mathrm{C}\left\{{ }^{1} \mathrm{H},{ }^{31} \mathrm{P}\right\}$ NMR $(125$ $\left.\mathrm{MHz}, \mathrm{CDCl}_{3}\right) \delta 26.3,27.0,61.9,70.7,70.8,81.2,82.3,82.9,85.0$, $112.8,127.2,127.29,127.33,127.4,127.5,127.8,128.0,128.3$, 128.9, 129.2, 141.5, 141.7, 146.2, 146.3. ${ }^{31} \mathrm{P}\left\{{ }^{1} \mathrm{H}\right\}$ NMR $(162 \mathrm{MHz}$, $\left.\mathrm{CDCl}_{3}\right) \delta 134.6(\mathrm{~s})$. HRMS $\left(\mathrm{ESI}^{+}\right) \mathrm{m} / z$ calcd for $\mathrm{C}_{70} \mathrm{H}_{72} \mathrm{O}_{13} \mathrm{P}_{2} \mathrm{Na}[\mathrm{M}+$ $\mathrm{Na}^{+}$1205.4340, found 1205.4339. Anal. Calcd. for $\mathrm{C}_{70} \mathrm{H}_{72} \mathrm{O}_{13} \mathrm{P}_{2}$ : C, 71.05; H, 6.13. Found: C, 71.85; H, 6.25.

General synthetic procedure for Pd-complexes based on bisphosphite ligands (8a and $8 \mathrm{c}$ ). A solution of enantiomerically pure bisphosphite ligand $\mathbf{1 a}$ or $\mathbf{1 c}(0.059 \mathrm{mmol})$ in dry $\mathrm{CH}_{2} \mathrm{Cl}_{2}(1.8$ $\mathrm{mL})$ was slowly added to a solution of $\left[\mathrm{PdCl}_{2}(\mathrm{cod})\right](0.054 \mathrm{mmol})$ in $\mathrm{CH}_{2} \mathrm{Cl}_{2}(0.2 \mathrm{~mL})$ at room temperature under inert atmosphere. The reaction mixture was stirred for $2 \mathrm{~h}$, after which the $\mathrm{CH}_{2} \mathrm{Cl}_{2}$ solvent was evaporated off until the mixture had one fourth of its original volume. Hexane $(15.0 \mathrm{~mL})$ was added, leading to the formation of a 
precipitate, which was filtered off and then washed with a small quantity of hexane $(1 \times 5.0 \mathrm{~mL})$ to give the desired Pd(II) complexes $\left[\mathrm{PdCl}_{2}(\mathbf{1})\right]$ as yellowish powders.

Compound 8a. Palladium complex 8a was prepared following the general procedure, starting from ligand $1 \mathrm{a}(117 \mathrm{mg}, 0.142 \mathrm{mmol})$ and $\left[\mathrm{PdCl}_{2}\right.$ (cod)] (37 mg, $\left.0.129 \mathrm{mmol}\right)$. It was obtained as a yellowish powder (27 mg, 20\% yield). $\mathrm{mp} 187.0-190.0{ }^{\circ} \mathrm{C}$. $[\alpha]_{\mathrm{D}}{ }^{25}-40.4(c 0.10$ in $\left.\mathrm{CH}_{2} \mathrm{Cl}_{2}\right) .{ }^{1} \mathrm{H}$ NMR $\left(500 \mathrm{MHz}, \mathrm{C}_{4} \mathrm{D}_{8} \mathrm{O}\right) \delta 3.65-3.85(12 \mathrm{H}, \mathrm{m})$, $4.23-4.26(2 \mathrm{H}, \mathrm{m}), 4.65-4.70(2 \mathrm{H}, \mathrm{m}), 6.75\left(2 \mathrm{H}, \mathrm{d},{ }^{3} J_{\mathrm{H}, \mathrm{H}}=8.8 \mathrm{~Hz}\right)$, 7.25-7.35 (8H, m), 7.44-7.47 $(2 \mathrm{H}, \mathrm{m}), 7.52-7.55(2 \mathrm{H}, \mathrm{m}), 7.63(2 \mathrm{H}$, $\left.\mathrm{d},{ }^{3} J_{\mathrm{H}, \mathrm{H}}=8.8 \mathrm{~Hz}\right), 7.77\left(2 \mathrm{H}, \mathrm{d},{ }^{3} J_{\mathrm{H}, \mathrm{H}}=8.9 \mathrm{~Hz}\right), 7.97\left(2 \mathrm{H}, \mathrm{d},{ }^{3} J_{\mathrm{H}, \mathrm{H}}=8.2\right.$ $\mathrm{Hz}), 8.06-8.08(4 \mathrm{H}, \mathrm{m}) .{ }^{13} \mathrm{C}\left\{{ }^{1} \mathrm{H}\right\}$ NMR $\left(125 \mathrm{MHz}, \mathrm{C}_{4} \mathrm{D}_{8} \mathrm{O}\right) \delta 70.8$, $71.5,71.7,72.0,121.8,122.0,122.6,123.6,126.6,126.8,127.6$, 127.7, 127.9, 129.4, 129.6, 131.9, 132.1, 132.8, 133.1, 133.2, 133.4, 147.1. ${ }^{31} \mathrm{P}\left\{{ }^{1} \mathrm{H}\right\} \quad \mathrm{NMR}\left(202 \mathrm{MHz}, \mathrm{C}_{4} \mathrm{D}_{8} \mathrm{O}\right) \quad \delta \quad 109.8$ (s). HRMS $\left(\mathrm{MALDI}^{+}\right.$) $\mathrm{m} / \mathrm{z}$ calcd for $\mathrm{C}_{48} \mathrm{H}_{40} \mathrm{O}_{9} \mathrm{P}_{2} \mathrm{ClPd}[\mathrm{M}-\mathrm{Cl}]^{+}$963.0865, found 963.0839. Anal. Calcd. for $\mathrm{C}_{48} \mathrm{H}_{40} \mathrm{O}_{9} \mathrm{P}_{2} \mathrm{Cl}_{2} \mathrm{Pd}$ : C, 57.65; H, 4.03 . Found: C, 57.33; H, 4.44 .

Compound 8c. Palladium complex 8c was prepared following the general procedure, starting from ligand $1 \mathrm{c}(70 \mathrm{mg}, 0.059 \mathrm{mmol})$ and $\left[\mathrm{PdCl}_{2}(\mathrm{cod})\right](15 \mathrm{mg}, 0.053 \mathrm{mmol})$. It was obtained as a yellowish powder $(47 \mathrm{mg}, 65 \%$ yield $) . \mathrm{mp} 210.2-214.9^{\circ} \mathrm{C} . \quad[\alpha]_{\mathrm{D}}{ }^{27}+160.6(c$ 0.04 in $\left.\mathrm{CH}_{2} \mathrm{Cl}_{2}\right)$. ${ }^{1} \mathrm{H}$ NMR $\left(500 \mathrm{MHz}, \mathrm{C}_{4} \mathrm{D}_{8} \mathrm{O}\right) \delta 0.41(6 \mathrm{H}, \mathrm{s}), 1.25$ $(6 \mathrm{H}, \mathrm{s}), 2.76-2.80(2 \mathrm{H}, \mathrm{m}), 2.86-2.91(2 \mathrm{H}, \mathrm{m}), 3.20-3.25(2 \mathrm{H}, \mathrm{m})$, $3.35-3.39(6 \mathrm{H}, \mathrm{m}), 3.54-3.60(2 \mathrm{H}, \mathrm{m}), 3.75-3.81(2 \mathrm{H}, \mathrm{m}), 5.07(2 \mathrm{H}$, $\left.\mathrm{d},{ }^{3} J_{\mathrm{H}, \mathrm{H}}=8.4 \mathrm{~Hz}\right), 5.74\left(2 \mathrm{H}, \mathrm{d},{ }^{3} J_{\mathrm{H}, \mathrm{H}}=8.4 \mathrm{~Hz}\right), 7.24-7.40(24 \mathrm{H}, \mathrm{m})$, 7.51-7.52 (4H, m), 7.72-7.74 (4H, m), 7.83-7.85 (8H, m). ${ }^{13} \mathrm{C}\left\{{ }^{1} \mathrm{H}\right\}$ NMR $\left(125 \mathrm{MHz}, \mathrm{C}_{4} \mathrm{D}_{8} \mathrm{O}\right) \delta 23.1,24.8,66.7,68.6,68.9,77.6,80.1$, $86.6,86.67,86.71,86.87,86.92,87.0,111.1,125.1,125.3,125.4$, $125.6,125.7,125.9,126.5,127.5,138.4,139.2,142.7,143.5 .{ }^{31} \mathrm{P}\left\{{ }^{1} \mathrm{H}\right\}$ NMR $\left(202 \mathrm{MHz}, \mathrm{C}_{4} \mathrm{D}_{8} \mathrm{O}\right) \delta 90.2(\mathrm{~s})$. HRMS $\left(\mathrm{ESI}^{+}\right) \mathrm{m} / \mathrm{z}$ calcd for $\mathrm{C}_{70} \mathrm{H}_{73} \mathrm{O}_{14} \mathrm{P}_{2} \mathrm{ClPd}[\mathrm{M}+\mathrm{OH}-\mathrm{Cl}]^{+} 1340.3213$, found 1340.3233. Anal. Calcd. for $\mathrm{C}_{70} \mathrm{H}_{72} \mathrm{O}_{13} \mathrm{P}_{2} \mathrm{Cl}_{2} \mathrm{Pd} \cdot 0.5 \mathrm{CH}_{2} \mathrm{Cl}_{2}: \mathrm{C}, 60.35 ; \mathrm{H}, 5.24$. Found: $\mathrm{C}$, 60.78; H, 5.68 .

General procedure for Pd-mediated allylic alkylation of rac-1,3-diphenylallyl acetate (2). A solution of $\left[\mathrm{Pd}(\mu-\mathrm{Cl})\left(\eta^{3}\right.\right.$ $\left.\left.\mathrm{C}_{3} \mathrm{H}_{5}\right)\right]_{2}(2.50 \mu \mathrm{mol})$ or $\left[\mathrm{PdCl}_{2}(\mathrm{cod})\right](5.00 \mu \mathrm{mol})$ and enantiopure bisphosphite $1(5.50 \mu \mathrm{mol})$ in $\mathrm{CH}_{2} \mathrm{Cl}_{2}(0.30 \mathrm{~mL})$ was stirred for 15 min. Subsequently a solution of 1,3-diphenylallyl acetate $\mathbf{2}(0.1$ $\mathrm{mmol})$ in $\mathrm{CH}_{2} \mathrm{Cl}_{2}(0.10 \mathrm{~mL})$, dimethyl malonate $(0.3 \mathrm{mmol}), \mathrm{N}, \mathrm{O}$ bis(trimethylsilyl)-acetamide $(0.3 \mathrm{mmol})$ and regulation agent (RA, $5.50 \mu \mathrm{mol}$; if appropriate) were added. The reaction mixture was stirred at room temperature for the appropriate reaction time. The reaction mixture was then diluted with $\mathrm{Et}_{2} \mathrm{O}(4.0 \mathrm{~mL})$ and washed with water $(2 \times 2.0 \mathrm{~mL})$. The organic phase was dried over $\mathrm{MgSO}_{4}$, filtered and concentrated in vacuo. The conversion was determined by ${ }^{1} \mathrm{H}$ NMR spectroscopy and the enantiomeric excess was determined by HPLC on chiral stationary phases (Daicel Chiralcel® OD-H, 99:1 $n$-hexane/2-propanol, $0.5 \mathrm{~mL} / \mathrm{min}, 216 \mathrm{~nm}) .{ }^{14}$

General procedure for Pd-mediated allylic amination of rac-1,3-diphenylallyl acetate (2). A solution of $\left[\mathrm{Pd}(\mu-\mathrm{Cl})\left(\eta^{3}\right.\right.$ $\left.\left.\mathrm{C}_{3} \mathrm{H}_{5}\right)\right]_{2}(2.50 \mu \mathrm{mol})$ and enantiopure bisphosphite $1(5.50 \mu \mathrm{mol})$ in $\mathrm{CH}_{2} \mathrm{Cl}_{2}(0.30 \mathrm{~mL})$ was stirred for $15 \mathrm{~min}$. Subsequently a solution of 1,3-diphenylallyl acetate $2(0.1 \mathrm{mmol})$ in $\mathrm{CH}_{2} \mathrm{Cl}_{2}(0.10 \mathrm{~mL})$, benzylamine $(0.3 \mathrm{mmol}), \mathrm{N}, \mathrm{O}$-bis(trimethylsilyl)-acetamide $(0.3 \mathrm{mmol})$ and regulation agent (RA, $5.50 \mu \mathrm{mol}$; if appropriate) were added. The reaction mixture was stirred at $\mathrm{rt}$ for the appropriate reaction time. The reaction mixture was then diluted with $\mathrm{Et}_{2} \mathrm{O}(4.0 \mathrm{~mL})$ and washed with water $(2 \times 2.0 \mathrm{~mL})$. The organic phase was dried over $\mathrm{MgSO}_{4}$, filtered and concentrated in vacuo. The conversion was determined by ${ }^{1} \mathrm{H}$ NMR spectroscopy and the enantiomeric excess was determined by HPLC on chiral stationary phases (Daicel Chiralcel® OD-H, 99:1 $n$-hexane/2-propanol, $0.6 \mathrm{~mL} / \mathrm{min}, 254 \mathrm{~nm}){ }^{15}$

General procedure for Pd-mediated allylic alkylation of cinnamyl acetate (5). A solution of $\left[\mathrm{Pd}(\mu-\mathrm{Cl})\left(\eta^{3}-\mathrm{C}_{3} \mathrm{H}_{5}\right)\right]_{2}(2.50$ $\mu \mathrm{mol})$ and enantiopure bisphosphite $1(5.50 \mu \mathrm{mol})$ in $\mathrm{CH}_{2} \mathrm{Cl}_{2}(0.30$ $\mathrm{mL}$ ) was stirred for $15 \mathrm{~min}$. Subsequently a solution of cinnamyl acetate $5(0.1 \mathrm{mmol})$ in $\mathrm{CH}_{2} \mathrm{Cl}_{2}(0.10 \mathrm{~mL})$, dimethyl malonate $(0.3$ $\mathrm{mmol}), \mathrm{N}, \mathrm{O}$-bis(trimethylsilyl)-acetamide $(0.3 \mathrm{mmol})$ and regulation agent (RA, $5.50 \mu \mathrm{mol}$; if appropriate) were added. The reaction mixture was stirred at $\mathrm{rt}$ for the appropriate reaction time. The reaction mixture was then diluted with $\mathrm{Et}_{2} \mathrm{O}(4.0 \mathrm{~mL})$ and washed with water $(2 \times 2.0 \mathrm{~mL})$. The organic phase was dried over $\mathrm{MgSO}_{4}$, filtered and concentrated in vacuo. The conversion was determined by ${ }^{1} \mathrm{H}$ NMR spectroscopy and the enantiomeric excess was determined by HPLC on chiral stationary phases (Daicel Chiralcel ${ }^{\circledR} \mathrm{OJ}-\mathrm{H}, 97: 3 n$ hexane/2-propanol, $0.7 \mathrm{~mL} / \mathrm{min}, 220 \mathrm{~nm}){ }^{14}$

\section{ASSOCIATED CONTENT}

\section{Supporting Information}

The Supporting Information is available free of charge on the ACS Publications website at DOI: 10.1021/acs.organomet.5b00962.

Text and figures giving characterization data, and NMR spectra for new compounds (PDF)

$$
\text { Crystallographic data for } \mathbf{8 a} \text { and } \mathbf{8 c} \text { (CIF) }
$$

\section{AUTHOR INFORMATION}

\author{
Corresponding Author \\ *E-mail: avidal@iciq.cat \\ Notes \\ The authors declare no competing financial interest.
}

\section{ACKNOWLEDGMENT}

The authors would like to thank MINECO (CTQ2014-60256-P) and the ICIQ Foundation for their financial support. L. R. is grateful to the ICIQ Foundation for her stipend. We would also like to thank Dr. J. Benet-Buchholz for the X-ray crystallographic data.

\section{REFERENCES}

(1) For selected reviews see: (a) Raynal, M.; Ballester, P.; VidalFerran, A.; van Leeuwen, P. W. N. M. Chem. Soc. Rev. 2014, 43, 1660-1733. (b) Raynal, M.; Ballester, P.; Vidal-Ferran, A.; van Leeuwen, P. W. N. M. Chem. Soc. Rev. 2014, 43, 1734-1787.

(2) (a) Gianneschi, N. C.; Bertin, P. A.; Nguyen, S. T.; Mirkin, C. A.; Zakharov, L. N.; Rheingold, A. L. J. Am. Chem. Soc. 2003, 125, 10508-10509. (b) Gianneschi, N. C.; Cho, S.-H.; Nguyen, S. B. T.; Mirkin, C. A. Angew. Chem. Int. Ed. Engl. 2004, 43, 5503-5507. (c) Sud, D.; Norsten, T. B.; Branda, N. R. Angew. Chem. Int. Ed. 2005, 44, 2019-2021. (d) Wang, J.; Feringa, B. L. Science 2011, 331, 14291432.

(3) (a) Bellini, R.; Chikkali, S. H.; Berthon-Gelloz, G.; Reek, J. N. H. Angew. Chem., Int. Ed. 2011, 50, 7342-7345. (b) Bellini, R.; Reek, J. N. H. Chem.-Eur. J. 2012, 18, 7091-7099. (c) Bellini, R.; Reek, J. N. H. Chem.-Eur. J. 2012, 18, 13510-13519.

(4) (a) Mon, I.; Jose, D. A.; Vidal-Ferran, A. Chem.-Eur. J. 2013 , 19, 2720-2725. (b) Vidal-Ferran, A.; Mon, I.; Bauza, A.; Frontera, A.; Rovira, L. Chem. - Eur. J. 2015, 21, 11417-11426. (c) Rovira, L.; Vaquero, M.; Vidal-Ferran, A. J. Org. Chem. 2015, 80, 10397-10403. (d) Fernández-Pérez, H.; Mon, I.; Frontera, A.; Vidal-Ferran, A. Tetrahedron 2015, 71, 4490-4494.

(5) (a) Clarke, M. L.; Fuentes, J. A. Angew. Chem. Int. Ed. 2007 46, 930-933. (b) Li, Y.; Ma, B.; He, Y.; Zhang, F.; Fan, Q.-H. Chem. Asian J. 2010, 5, 2454-2458. (c) van Leeuwen, P. W. N. M.; Rivillo, D.; Raynal, M.; Freixa, Z. J. Am. Chem. Soc. 2011, 133, 1856218565. (d) Dydio, P.; Rubay, C.; Gadzikwa, T.; Lutz, M.; Reek, J. N. H. J. Am. Chem. Soc. 2011, 133, 17176-17179. (e) Song, F.-T.; Ouyang, G.-H.; Li, Y.; He, Y.-M.; Fan, Q.-H. Eur. J. Org. Chem. 2014, 6713-6719. f) Ouyang, G.-H.; He, Y.-M.; Fan, Q.-H. Chem. Eur. J. 2014, 20, 16454-16457.

(6) For selected contributions see: (a) Trost, B. M.; Lee. C. Asymmetric Carbon-Carbon Bond-Forming Reactions: Asymmetric Allylic 
Alkylation Reactions. In Catalytic Asymmetric Synthesis; Ojiwa, I., Ed.; Wiley-VCH: New York, 2000, Vol. 8e, pp 593-649. (b) Trost, B. M.; Zhang, T.; Sieber, J. D. Chem. Sci. 2010, 1, 427-440.

(7) For selected contributions see: (a) Trost, B. M.; Crawley, M. L. Chem. Rev. 2003, 103, 2921-2944. (b) Gavrilov, K. N.; Bondarev, O. G.; Polosukhin, A. I. Russ. Chem. Rev. 2004, 73, 671-699. (c) Takacs, J. M.; Reddy, D. S.; Moteki, S. A.; Wu, D.; Palencia, H. J. Am. Chem. Soc. 2004, 126, 4494-4495. (d) Lu, Z.; Ma, S. Angew. Chem., Int. Ed. 2008, 47, 258-297. (e) Diéguez, M.; Pàmies, O. Acc. Chem. Res. 2010, 43, 312-322. (f) Grabulosa, A.; Doran, S.; Brandariz, G.; Muller, G.; Benet-Buchholz, J.; Riera, A.; Verdaguer, X. Organometallics 2014, 33, 692-701.

(8) (a) El Gihani, M. T.; Heaney, H. Synthesis 1998, 357-375. (b) Trost, B. M.; Murphy, D. J. Organometallics 1985, 4, 1143-1145.

(9) Reetz, M. T.; Mehler, G.; Bondarev, O. Chem. Commun. 2006, 2292-2294.

(10) Jose, D. A.; Mon, I.; Fernandez-Perez, H.; Escudero-Adan, E. C.; Benet-Buchholz, J.; Vidal-Ferran, A. Org. Lett. 2011, 13, 36323635 .

(11) The ${ }^{31} \mathrm{P}\left\{{ }^{1} \mathrm{H}\right\}$ NMR chemical shift for $\mathbf{8 a}$ is similar to that previously reported for a related Pd-complex. See: Sheff, J. T.; Lucius, A. L.; Owens, S. B.; Gray, G. M. Organometallics 2011, 30, 56955709.

(12) See the Supporting Information for details.

(13) Wassenaar, J.; de Bruin, B.; Reek, J. N. H. Organometallics 2010, 29, 2767-2776.

(14) Popa, D.; Puigjaner, C.; Gómez, M.; Benet-Buchholz, J.; Vidal-Ferran, A.; Pericàs, M. A. Adv. Synth. Catal. 2007, 349, 22652278.

(15) Popa, D.; Marcos, R.; Sayalero, S.; Vidal-Ferran, A.; Pericàs, M. A. Adv. Synth. Catal. 2009, 351, 1539-1556. 
TOC graphic:

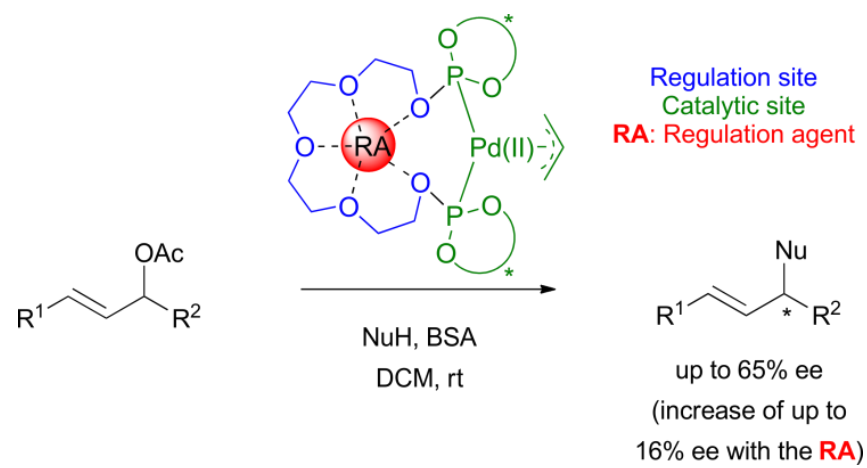

